\title{
Ró - Cerrados e Mundo A'uwe Xavante
}

\author{
Maria Lucia Cereda Gomide*
}

\section{Resumo}

O povo Xavante vive atualmente no estado do Mato Grosso, em nove terras indígenas que são fragmentos de seu território original e ainda guardam a biodiversidade dos cerrados.

As relações do Xavante com os cerrados serão o objeto de discussão deste artigo. Neste sentido é comentado o conceito de Ró, que para os Xavante significa "cerrados, mundo, nossa terra, tudo", enfim é um complexo que se configura espacialmente por meio de círculos concêntricos que vão desde a aldeia até os cerrados e seus espíritos.

Salienta-se a importância dos cerrados na cosmologia e na visão de natureza desse povo, destaca-se ainda as classificações indígenas das fitofisionomias dos cerrados.

Palavras-chave: Xavante, cerrados, modo de vida, classificações indígenas.

\section{Abstract}

\section{Ró - brazilian savanna and world A'uwe Xavante}

The Xavante people live in what is now the western Brazilian state of Mato Grosso, on nine indigenous reservations that are fragments of their original territory, characteristic for its still untouched biodiversity and cerrado, a scrub-like ecosystem endemic to Brazil.

This article discusses the relationship between the Xavante and the cerrado, and, accordingly, the concept of Ró is discussed, which for the Xavante means "cerrado, world, our land, everything". In summary, it is a complex that is configured spatially through concentric circles that spread out from villages to the cerrado and its spirits.

The importance of the cerrado with regards to their cosmology and their vision of Mother Nature is also emphasized, along with indigenous classifications for the phytophysiognomy of the cerrado.

Keywords: Xavante, cerrado, lifestyle, indigenous classifications.

\section{Introdução}

O objeto de discussão deste artigo são as relações dos $A^{\prime} u w e$ Xavante com os cerrados. Salienta-se a importância dos cerrados na cosmologia e a visão de natureza desse povo destacando-se o complexo conceito de Ró, o qual é a representação de seu território/mundo, configurando uma espacialidade por meio de círculos concêntricos. Comenta-se também as classificações indígenas de animais e vegetais que compõe os cerrados.

O Xavante pertence ao grupo linguístico 
Akuen do tronco Macro-Jê, sua autodenominação é A'uwe ("gente"). Alguns autores como Graham (2008) e Maybury-Lewis (1984), consideram que Akuen ou Acuen refere-se aos Xavante e Xerente. Os Akuen, que tinham seu território no centrooeste brasileiro, eram conhecidos na época da colônia como Tapuias, enquanto os Tupi eram denominados Tamoios. Os A'uwe Xavante não têm nenhuma proximidade histórica, linguística ou sociológica com os Oti-Xavante -SP ou com os Ofaié-Xavante -MS.(MAYBURY-LEWIS, 1984; GRAHAM, 2008).

O contato dos Xavante com a sociedade envolvente ocorreu em diferentes momentos, pois as cisões políticas determinaram que os vários grupos Xavante realizassem trajetórias distintas. $O$ período de sua História de meados do século XIX até recentemente, refere-se aos grupos Xavante que passaram a viver no Mato Grosso, após as travessias dos rios Araguaia, Cristalino e das Mortes (anteriormente denominado de rio Manso).

A vivência na bacia do rio das Mortes deixou-os em certo isolamento até próximo dos anos 1940, quando são novamente contatados e sua pacificação é oficializada pelo Estado brasileiro.

De modo geral, segundo Lopes da Silva (1992), pode-se resumir os principais fatos da história Xavante do século XX, da seguinte forma:

- Durante as primeiras décadas do século $X X$, os Xavante, já no estado do Mato Grosso, vivem um período de tranquilidade;

- Década de 1940, início da ocupação da fronteira agrícola centro-oeste sob a ideologia da ocupação de espaços "vazios" e conquista de territórios, com a "Marcha para o Oeste" através da Expedição Roncador Xingu e da Fundação Brasil Central;

- Décadas de 1940-50 a "pacificação oficial" de um grupo Xavante, às margens do rio das Mortes; e período de certo distanciamento na década 1960; A partir deste período os Xavante passam a viver o confinamento territorial e o contato constante com o "branco", "o panorama antes vasto, fecha-se". Assim seu "microuniverso" (LOPES DA SILVA, 1992:373) é caracterizado pela convivência cotidiana com os postos indígenas e as missões, determinando as relações interétnicas que passaram a vivenciar. - Anos 1970 e 80 o foco são as regularizações das terras indígenas Xavante com a importante liderança de Mario Juruna- Dzuru'rã, e a imagem dos Xavante como "índios conscientes e reivindicadores". Segundo Lopes da Silva, (1992:358), os Xavante são reconhecidos como "sabedores do valor de seu próprio universo cultural e dispostos a defendê-lo, conhecedores de seus direitos e prontos a preservá-los ou recuperá-los." Os Xavante reconquistam partes do território em Parabubure, Pimentel Barbosa e Areões Sangradouro/Volta Grande (ver figuras).

Os contextos em que foram construídas e demarcadas são acentuadamente distintos, e portanto, o contato e seus impactos foram sentidos de formas diferenciadas em cada uma destas terras indígenas.

$\mathrm{Na}$ atualidade, em termos populacionais, os Xavante caracterizam-se por ser um dos maiores entre os povos indígenas do Brasil. Entretanto, muitas enfermidades acometeram os Xavante, algumas diretamente relacionadas ao confinamento territorial, como aquelas ligadas à precariedade no saneamento básico, principalmente falta de tratamento da água. (CARRARA, 1997) fato este que leva ao agravamento do quadro de desnutrição das crianças, apresentando altas taxas de mortalidade infantil, principalmente na faixa de 0 a 5 anos de idade.

\section{A área de estudo}

A área de estudo são as terras indígenas Xavante (doravante utilizaremos T.I. para Terra Indígena), que são fragmentos do seu território tradicional. As nove Terras Indígenas estão localizadas no estado do Mato Grosso: T. I.Marãiwatsede, T. I.Pimentel Barbosa, T. I.Areões (Areões I,Areões II), T. I. Marechal Rondon, T. I. Parabubure, T. I. Chão Preto, T. I. Ubawawe, T. I. Sangradouro/Volta Grande, T. I. São Marcos.

Devido à intensa ocupação dos cerrados matogrossenses pela pecuária e agricultura de grãos, as terras indígenas Xavante são na atualidade ilhas de biodiversidade cercadas por extensas áreas degradadas. 
Tabela 1 - Terras Indígenas Xavante: área (ha), situação fundiária e localização

\begin{tabular}{|c|c|c|c|}
\hline TERRA INDÍGENA & $\begin{array}{c}\text { ÁREA } \\
\text { (HECTARES) }\end{array}$ & MUNICÍPIO & $\begin{array}{c}\text { SITUAČ̃̃O } \\
\text { FUNDIÁRIA }\end{array}$ \\
\hline $\begin{array}{l}\text { T. I. Marãiwatsede } \\
\text { T. I. Pimentel }\end{array}$ & $\begin{array}{r}168.000 \\
328.966\end{array}$ & Alto da Boa Vista & Homologada \\
\hline Barbosa & & Canarana & \\
\hline T. I. Areões & 218.515 & Nova Xavantina & Homologada \\
\hline T. I. Areões I & 24.450 & Água Boa & Demarcada \\
\hline T. I. Areões II & 16.650 & Água Boa & Demarcada \\
\hline T. I. Marechal Rondon & 98.500 & Paranatinga & Demarcada \\
\hline T. I. Parabubure* & 224.447 & Campinápolis & Homologada \\
\hline Chão Preto & 8.060 & Campinápolis & Homologada \\
\hline Ubawawe & 51.900 & Novo São Joaquim & Homologada \\
\hline T. I. Sangradouro & 100.280 & General Carneiro & Homologada \\
\hline T. I. São Marcos & 188.478 & Barra do Garças & Demarcada \\
\hline
\end{tabular}

Observação: A T. I. Parabubure teve seus limites revistos com a regularização das T.I. Chão Preto e Ubawawe - Fonte: ISA, 2008

Tabela 2 - Dinâmica da População em cada terra indígena

\begin{tabular}{|c|c|c|c|c|c|c|c|c|c|}
\hline $\begin{array}{l}\text { TERRA } \\
\text { INDÍGENA/ }\end{array}$ & 1977 & 1980 & 1984 & 1988 & 1996 & 1998 & 2000 & 2002 & 2003 \\
\hline T.I.Pin & 266 & 269 & 526 & 673 & 1.068 & 1.139 & 1.361 & 1.482 & 1.570 \\
\hline $\begin{array}{l}\text { Barbosa } \\
\text { T.I.Areões } \\
\text { T.I.Areões I } \\
\text { T.I.Areões II }\end{array}$ & 303 & 347 & 511 & 594 & 759 & 855 & 913 & 1.014 & 1.028 \\
\hline $\begin{array}{l}\text { T.I.Marechal } \\
\text { Rondon }\end{array}$ & 111 & 120 & 215 & 237 & 376 & 447 & 433 & 480 & 500 \\
\hline $\begin{array}{l}\text { T.I.Parabubure } \\
\text { Chão Preto } \\
\text { Ubawawe }\end{array}$ & 1.066 & 1.179 & 2.104 & 2.697 & 3.162 & 4.320 & 3.883 & 4.229 & 4.502 \\
\hline $\begin{array}{l}\text { T.I.Sangradouro } \\
\text { T.I.São Marcos }\end{array}$ & $\begin{array}{r}548 \\
1.010\end{array}$ & $\begin{array}{l}497 \\
993\end{array}$ & $\begin{array}{r}446 \\
1.032\end{array}$ & $\begin{array}{r}524 \\
1.366\end{array}$ & $\begin{array}{r}807 \\
1813\end{array}$ & $\begin{array}{l}1.156 \\
2.304\end{array}$ & $\begin{array}{r}933 \\
2.078 \\
\end{array}$ & $\begin{array}{l}1.021 \\
2.251\end{array}$ & $\begin{array}{l}1.188 \\
2.443\end{array}$ \\
\hline $\begin{array}{l}\text { T.I. } \\
\text { Marãiwatsede* } \\
\text { Total }\end{array}$ & 3.304 & 3.405 & 4.834 & 6.091 & 7.985 & 10.221 & 9.601 & & 11.231 \\
\hline
\end{tabular}

*Obs: A T. I. Parabubure teve seus limites revistos com a regularização das T.I. Chão Preto e Ubawawe Fonte: ISA, 2008 
Figura 1- Terras Indígenas Xavante no Mato Grosso

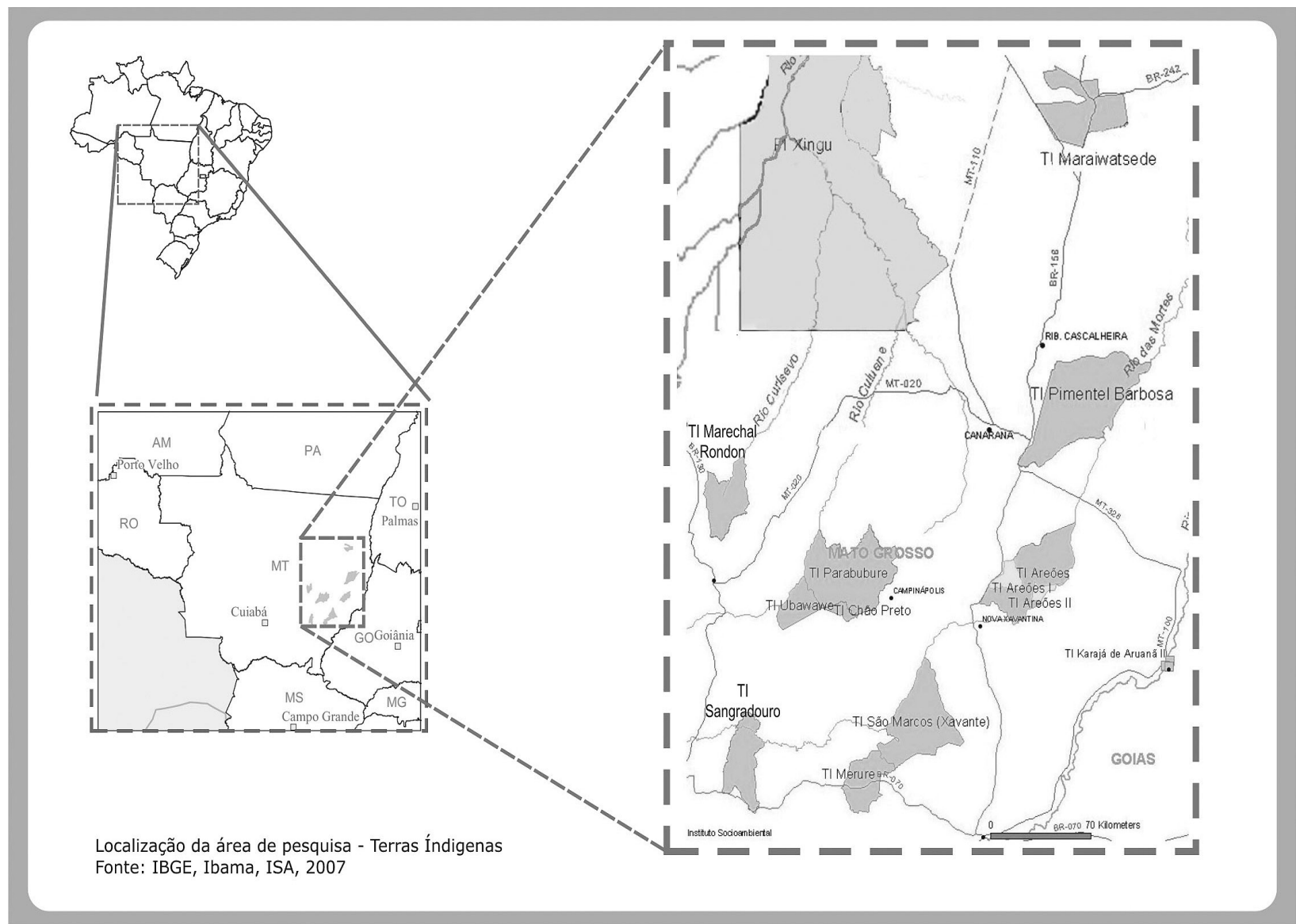

Org.: Maria Lucia C. Gomide e Marcelo Silva.

\section{Procedimentos metodológicos do trabalho}

A pesquisa fundamenta-se nos procedimentos da pesquisa participante, isto é, no conhecimento adquirido ao longo dos anos de trabalho como parceira da Associação Xavante Warã, por meio de projetos iniciados no ano 2000 na comunidade da aldeia Idzou'hu (T. I.Sangradouro). Assim, os primeiros projetos foram desenvolvidos na T.I. Sangradouro enquanto os últimos tiveram um caráter mais participativo e ao mesmo tempo um diferencial ao ampliarem-se para quatro Terras Indígenas Xavante (Sangradouro,
São Marcos, Areões e Pimentel Barbosa).

O projeto "Öwawe Waihömanadze" ("o rio das Mortes é nossa vida"), em 2006, foi sem duvida a oportunidade mais importante para o enfoque da pesquisa. Durante a primeira parte de seu desenvolvimento realizou-se uma viagem pelo rio das Mortes com o objetivo de levantar a situação socioambiental da bacia hidrográfica do rio das Mortes, tanto no entorno quanto nos limites das terras Xavante aí inseridas, o trecho onde situamse as terras indígenas Areões e Pimentel Barbosa.

Desta forma foram feitos contatos com os Xavante, construindo uma relação de confiança e 
de amizade, e ao mesmo tempo de compromisso político. Desta experiência pessoal muito me tocou a triste realidade daquilo que foi um dia os cerrados brasileiros, hoje reduzidos a poucos fragmentos, sendo que no leste matogrossense as maiores manchas de cerrado são as terras indígenas.

Buscou-se então entender esta contradição entre dois mundos, e os desafios ambientais da permanência dos Xavante nos cerrados.

Assim partindo dos questionamentos das lideranças de Idzou'hu, em um movimento de interesse próprio de (re)construção da História Xavante na bacia do rio das Mortes, e valorização das tradições culturais relacionadas ao uso dos recursos naturais de seus territórios é que pudemos nos inserir e construir as questões acadêmicas. Neste contexto é que se parte de uma ação para chegar a uma pesquisa.

$O$ acesso às informações, portanto, se deu feito por meio dos dados produzidas ao longo da vivencia de projetos. Como exemplo as inúmeras entrevistas, depoimentos, traduções e transcrições de gravações feitas pelos próprios Xavante, considerando assim como as principais fontes documentais deste trabalho.

Lembrando as palavras de Brandão (2001;p. 54-55), para se obter "ritmo e equilíbrio de ação-reflexão" é necessário que o conhecimento faça um movimento espiral, no qual o "pesquisador vai das tarefas mais simples para as mais complexas e do conhecido para o desconhecido, em contato permanente com as bases sociais. [...] em seguida os dados são restituídos as bases de uma forma mais consistente e ordenada, estudam-se as conseqüências desta restituição, e assim por diante, indefinidamente mas de maneira equilibrada, determinada pela própria luta e por suas necessidades."

Para que este movimento se realize é também necessário ao pesquisador :

a- "abandonar a tradicional arrogância do erudito, aprender a ouvir discursos concebidos em diferentes sintaxes culturais, e adotar a humildade dos que realmente querem aprender e descobrir;

b- romper com a assimetria das relações sociais geralmente impostas entre entrevistador e o entrevistado;

c- incorporar pessoas de bases sociais como indivíduos ativos e pensantes nos esforços de pesquisa." (BRANDÃO, 2001, p. 55)

Ainda nesta discussão Clifford (2002), explica que muitos etnógrafos observam que suas pesquisas foram "direcionadas ou circunscritas por seus informantes. Na verdade qualquer exposição etnográfica contínua inclui rotineiramente em si mesma uma diversidade de descrições, transcrições e interpretações feitas por uma variedade de 'autores' indígenas."

Dentro deste raciocínio, este autor, questiona qual a maneira de se colocar estas presenças autorais no trabalho, e comenta que uma forma comum é citar tais informantes. Além disto vem sendo possibilitado aos leitores indígenas acesso às etnografias.

O autor informa, ainda, que

"é intrínseco à ruptura da autoridade monológica que as etnografias não mais se dirijam a um único tipo geral de leitor.[...] com o recente questionamento dos estilos coloniais de representação, com a expansão da alfabetização e da consciência etnográfica, novas possibilidades de leitura das descrições culturais estão surgindo." (CLIFFORD, 2002, p. 47-49 e 56-58).

$\mathrm{Na}$ proposta metodológica da "pesquisa participante" destaca-se, a seguir, alguns aspectos relevantes ao desenvolvimento deste método.

Das análises de Brandão (1981, 1987), sobre a pesquisa participante, apreende-se que este é um método e também uma atitude, o qual iniciou-se como "observação participante", com o trabalho de Malinowski ${ }^{1}$ (que constrói uma explicação da cultura e da sociedade Trobiandesa a partir de sua vivência entre eles). Brandão explica também que é a partir da obra de Marx que este método ganha uma conotação política e de compromisso "mais do que conhecer para explicar, a pesquisa pretende compreender para servir"(BRANDÃO,1987). Este momento marca um novo nexo do trabalho cientifico à participação da pesquisa: "Quando o outro se transforma em uma convivência, a relação obriga a que o pesquisador participe de sua vida, de sua cultura. Quando o outro me transforma em um compromisso a relação obriga a que o pesquisador participe de sua História."( BRANDÃO,1987:11) 
Ao transformar a pesquisa em um compromisso "traduzida em trabalho político", transforma-se também a própria vida:

" [...] A participação não envolve uma atitude do cientista para conhecer melhor a cultura que pesquisa. Ela determina um compromisso que subordina o próprio projeto cientifico de pesquisa ao projeto político dos grupos populares cuja situação de classe, cultura ou História se quer conhecer porque se quer agir." (BRANDÃO [1981], 2001, p. 12)

A pesquisa participante no Brasil e na América Latina surgiu na década de 1970, quando vários paises latino-americanos viviam a realidade dos regimes autoritários, desenvolvimentistas e excludentes do ponto de vista socioeconômico, além de ambientalmente degradante. (GAJARDO, 1987, p. 39)

No movimento da pesquisa-participante, desenvolvem-se dois eixos, um educativo e outro sociológico, à Paulo Freire reconhece-se a primazia pela introdução do conceito de investigação-ação na educação, muitas vezes também transposto para outros campos de conhecimento.

Deve ser salientado que esta proposta metodológica traz uma crítica aos métodos que eram então utilizados nas ciências sociais, de base positivista, (na qual a subjetividade do pesquisador era proibida àqueles que buscassem o rigor do método cientifico), que mantinham o pesquisador a uma distancia da realidade social e política, e ainda manipulação do conhecimento e das informações. A investigação-ação é então uma proposta para um caminho alternativo de ação e compromisso. (BRANDÃO, 1987, p. 23)

Fundamental nas abordagens participativas é o colombiano Orlando Fals Borda, que também faz a critica à ciência 'neutra' e traz como proposta a 'ciência popular' com base no conhecimento empírico da sociedade. (Fals Borda,1980; Rodrigues, 2001)

Entre os diversos autores que discutem a pesquisa participante, Guy Le Boterf (1987, p.52), em suas reflexões discute que a pesquisa tradicional, positivista, é limitante, pois não considera que a população pesquisada seja capaz de realizar uma crítica aos seus problemas, e apontar soluções aos mesmos. Ressalta ainda que na pesquisa tradicional, a analise crítica fica a cargo de 'especialistas'. Na perspectiva da pesquisa participante é o ponto de vista da comunidade ou grupo estudado que tem importância acerca das situações vividas. "Qual a percepção destes sobre tais situações? Como eles as interpretam? Qual o seu sistema de valores? Quais os seus problemas? Quais as suas preocupações? É necessário aí apreender qual é a lógica dos pesquisados [...]", (Le Boterf, 1987, p. 57-58) acrescenta-se ainda quais propostas e soluções propõem para seus problemas?

Além disto é enfatizada a necessidade do contato ao partilhar o cotidiano da comunidade estudada, considerando o seu espaço e o seu tempo, aproximando assim da "pesquisa em ritmo lento" do etnólogo, muitas vezes de longo tempo até que se adquira a confiança necessária.

Uma interessante analise sobre a participação e seus significados é a tese de $\operatorname{Rodrigues}(2001)^{2}$ que analisa os programas de gestão ambiental em áreas protegidas, a autora mostra que de certa forma "as bases teórico metodológicas da pesquisa participante clássica" exerceram influência nas metodologias participativas de vários países durante os anos 1980. No entanto, atualmente, o objetivo maior de "emancipação social que movia aquelas práticas não é mais observada na maioria das experiências" ${ }^{\prime 3}$, sendo que as atuais proposta das metodologias participativas postas em pratica tem a função de atuar e "instrumentalizar processos de planejamento". (RODRIGUES, 2001:16-7)

De acordo com Clifford (2002), o método etnográfico é representado pela observação participante, que surgiu de uma fusão entre a "experiência pessoal intensa e análise científica", embora entendido de maneiras diferentes, este método caracteriza a antropologia.

"a observação participante serve como uma fórmula para o contínuo vaivém entre o interior e o exterior dos acontecimentos: de um lado, captando o sentido de ocorrências e gestos específicos, através da empatia; de outro, dá um passo atrás , para situar esses significados em contextos mais amplos." (CLIFFORD, 2002, p. 32- 34) 
O trabalho de Siqueira 2007, é utilizado aqui como referência para comentar a metodologia participativa no campo da antropologia. É ressaltando-se que a antropologia da ação está baseada no "comprometimento com os interesses indígenas" e que portanto distinguese da antropologia aplicada. (Cardoso de Oliveira [1975] 1978 apud SIQUEIRA,2007) O mesmo autor ao falar sobre a antropologia da ação, explica que este termo foi primeiramente usado pelo antropólogo Tax (1951), que mostrou a importância de "se conhecer as percepções nativas frente às alternativas de mudança, por ser por meio delas que as sociedades se orientariam para reagir às mudanças. É exigido do antropólogo da ação um compromisso, assumido como valor, com a liberdade que uma comunidade deve ter na escolha do seu próprio modo de vida.[...]"(SIQUEIRA, 2007, p.18-19 e 20-21)

Neste movimento da antropologia da ação, foi defendida a participação direta dos povos indígenas nas decisões de seus próprios destinos pelos antropólogos que coordenavam os projetos. Significando um compromisso com as populações indígenas no sentido de sua autogestão com o fim de torná-los independentes da FUNAI. Os antropólogos ligados a antropologia da ação foram fundamentais para a formação das lideranças indígenas brasileiras. "A preocupação desses antropólogos da ação, portanto, era a de que suas intervenções não fossem confundidas com as praticas colonialistas e imperialistas que marcaram a História da antropologia, com o rotulo de antropologia aplicada." (SIQUEIRA, idem). Atualmente 0

"engajamento e a intervenção antropológica constituem, cada vez mais, uma dimensão social e política elementar do trabalho de campo dentro da etnologia das minorias - muitas vezes relegada a um plano inferior. A antropologia está, assim, cada vez mais orientada, no curso das últimas décadas, para um tipo de pesquisa onde o projeto histórico dessas sociedades face ao Estado define um parâmetro fundamental da pesquisa."(Siqueira, 2007, p.20)
Muitos geógrafos que pesquisam comunidades tradicionais e outras questões ligadas aos saberes das populações utilizam-se de métodos etnográficos, além de outros, tais métodos como História oral, História de vida, observação participante. Entre estes podem ser citados os trabalhos de Furlan (2000), Ferreira (2002), Rezende $(2004,2008)$, Cavalieri (2004), etc.

\section{Os cerrados e o Mundo A'uwe Xavante}

Paul Claval (1995, p. 368) aponta para as perspectivas em Etnogeografia, destacando que, "o método etnogeográfico reconstitui inicialmente a percepção que os homens têm do mundo. Quais são os fatores que ligam os elementos da cultura? Quais são os princípios que estruturam o espaço e se superpõe ao caos original uma ordem inteligível?". Neste sentido levanta as seguintes questões:

1. como o meio é percebido pelos habitantes?

2. graças a que o meio é apreciado?

3. como conceberam a ordem social e as regras e nomes com os quais dão conformação ao espaço?"

Segue-se esta trilha elaborada por Claval, na tentativa de compreensão das relações com os cerrados.

Os Xavante estabelecem uma ordem quando descrevem o Ró (cerrado,mundo), como um complexo concêntrico onde o mais interior é a aldeia, o quintal, e logo depois as roças seguido pelos cerrados (com as plantas e animais e com os espíritos). Essa configuração dos círculos concêntricos é ao mesmo tempo um continuum, no sentido de que cada uma das partes tem limites fluidos.

O círculo representa a figura ideal de igualdade e de intensidade da vida social. (LOPES DA SILVA, 1983), e possui, portanto, uma simbologia especial para as sociedades Jê como já analisado por autores como Vidal (1978); Maybury Lewis (1984); Novaes (1983); Ladeira,M.E.(1983); Da Matta (1976) e Lopes da Silva $(1986,1983)$.

"A maior parte dos povos indígena do Brasil Central dispõe as suas casas de modo dar à aldeia uma 
forma circular. Da Matta demonstrou que, mesmo vivendo em casas construídas ao longo de ruas, alinhadas paralelamente, os Apinayé continuam a pensar a sua aldeia e a representá-la de forma circular (1976:61-8). [...] todos os Timbira e também todos os Kayapó (Vidal 1978:60-76) vêem no círculo a disposição ideal de suas casas. Os Xavante [...] levam a idéia um pouco além: não só as aldeias, como a própria planta de suas casas tradicionais, são circulares." (LOPES DA SILVA, 1986, p. 35-36)

As palavras dos Xavante expressam a importância das formas circulares, "O povo Xavante preza muito as formas circulares. 0 circulo simboliza a coletividade, assim as danças são realizadas em roda, as casas são redondas e a própria aldeia é arredondada. Na verdade a aldeia tem a forma de ferradura, é um circulo que não se fecha." (RURIÕ \& BIASE, 2000)

Assim, por meio de círculos concêntricos é concebido o espaço do Ró. Este é um conceito fundamental para entendermos a noção de território Xavante, associado à noção de mundo e, portanto, onde se estabelecem relações que determinam um modo de ser, ou gênero de vida. (LADEIRA, 2001:109)

O Ró não é apenas uma fonte de recursos mas deve ser entendido como a espacialização das relações entre os diferentes sujeitos que habitam o cosmos.

\section{Ró: os Cerrados - Lugar e Mundo}

Antigamente o Ró (cerrados) era assim: havia a aldeia, em volta a roça, em volta as frutas, em volta a caça junto com os espíritos, em volta mais caça e mais caça sempre junto com os espíritos. Os espíritos ajudavam a descobrir os segredos que o Ró escondia: onde estava a força do caçador, onde estava a caça, onde tinha cobra e outros segredos". [...]"O A'úwê (Xavante) depende do cerrado e o cerrado depende do A'úwê (Xavante). Os animais dependem do cerrado e o cerrado depende dos animais. Os animais dependem do A'úwê (Xavante) e o A'úwê (Xavante) depende dos animais. Isso é o Ró." (TOP'TIRO Xavante e TSERETSU Xavante , 2000)
Ró significa tudo para os caçadores $A^{\prime}$ úwê (Xavante): o cerrado, os animais, os frutos, as flores, as ervas, o rio e tudo mais. Nós queremos conservar o Ró. Através do Ró garantiremos o futuro das novas gerações" (TOP' TIRO Xavante, 2000)

Os cerrados são concebidos pelos Xavante como a condição indispensável para o exercício de seu modo de vida. Neste sentido, a importância dos Cerrados na cultura Xavante, é entendida, pois os Cerrados são "apropriado material e simbolicamente pelos Xavante que, através dessa interação, sobrevivem física e culturalmente." (CARRARA, 1997)

Para se compreender o sentido dos cerrados na cultura Xavante é necessário que se conheça o mito Parinai'a ${ }^{3}$ e sua relação com a construção do território e dos cerrados Xavante. Neste mito dois wapté (adolescentes) são os criadores dos seres dos cerrados, esta energia criativa esta relacionada com a resistência dos wapté, que experimentando a sua própria força realizam a superação espiritual. Para os Xavante, os wapté estão associados à criatividade, fertilidade e potência sexual. (MAYBURY-LEWIS, 1984)

Lopes da Silva (1986) analisou a importância deste mito, e escreveu sobre os aspectos relacionados aos wapté no mito Parinai'a. "[...] Criadores porque mediadores entre natureza e cultura. Criadores porque cristalização de uma aliança entre opostos".

O "Parinai'a determina o território porque é a marca dos alimentos, onde foram criados, por exemplo onde estão os carás nativos (moõ'ni) que são alimentos importantes na dieta Xavante." (TOP'TIRO ${ }^{4}$, 2007)

As suas criações são identificadas com vários elementos fundamentais da cultura Xavante, até a própria configuração do território e mundo Xavante :
a) criam a Serra do Roncador delimitando o território;

b) criam rituais - a corrida de tora de buriti - elementos vitais para a organização social do grupo, a classificação das pessoas e para a permanência da sociedade como um todo. 
(LOPES DA SILVA, op.cit. 226-8)

Nas versões desse mito registradas por Giaccaria \& Heide (1975), Lopes da Silva (1974), e a relatada por Sereburã (1999), são narradas as criações dos dois heróis Xavante. Assim, criam os Cerrados, desde os frutos, os animais até o próprio relevo são obras suas. Neste sentido é que se forma a configuração do território Xavante, pois através destas criações são formadas as fisionomias do cerrado, as águas e as matas até a Serra do Roncador, nas relações com este espaço que os Xavante têm o exercício da territorialidade.

De acordo com Giaccaria \& Heide (1975, p. 45) neste mito " dois rapazes eram dotados de um dom especial. Podiam, em conjunto e com o poder da palavra, criar tudo o que desejassem, inclusive transformarem-se, tomando formas de animais." Seguem-se trechos do livro "Jerônimo Xavante Conta" de Giaccaria \& Heide (1972) :

"há muito tempo, nossa gente vivia na selva, e dela tirava seus alimentos. Todos os dias os homens e os rapazes saíam à sua procura. Essa tarefa não era fácil, pois as árvores não davam frutos. Colhiam pau mofo e caçavam. À noite, reencontravam se num lugar predeterminado e aí acampavam, distribuindo em seguida os resultados da batida. Estes eram os alimentos de nosso povo no início. Ora, entre os rapazes, dois eram dotados de um dom especial. Podiam em conjunto e com o poder da palavra, criar tudo o que desejassem, inclusive transformarem se tomando formas de animais. Eles saindo para as caçadas, usando deste dom, começaram a criar ora uma coisa, ora outra. Colhiam em abundância e comiam. Depois levavam grandes quantidades para o acampamento para todos que lá estavam."

Da versão de Lopes da Silva coletada em 1974, na aldeia Paraíso, reproduzimos trecho deste mito em que se descreve a criação da Serra do Roncador:

Então Parinai'a falou para o companheiro: -Como que nós vamos fazer?

-Deixe os outros sair na frente, nós não precisamos sair juntos.
-Então todo mundo saiu. Depois saíram os dois rapazes. Um perguntou para o outro:

-Como podemos fazer agora?

-Eu não sei não, que você está achando?

- Vamos criar a mina, a serra, assim fecha trilheiro, gente não precisa passar mais. Vamos criar varjão também.

- Aí, depois, todos os dois aceitaram. Vai colocar mesmo a mina, a serra. Depois fez muito comprida a serra assim. [referência à Serra do Roncador].

- Aí, depois começou a corrida de buriti. Aí, vai entregando para o outro, para o outro, entregando, entregando, até encontrar a serra.

- Como tem serra aqui? Nós passamos aqui e era tudo campo limpo, agora tem serra? O que é isso?

- Ninguém tinha percebido que eram os dois rapazes que estavam criando as coisas $[\ldots]^{\prime \prime}$

Sereburã et. alii(1999) também contam a história dos criadores, como ocorre a criação dos cerrados e reitera a condição de que percorriam o território em zomori (expedição de caça e coleta), sempre andando.

"Antigamente o povo A'uwe era nômade, vivia em zomori, andando sempre, percorrendo todo o território. Naquele tempo ainda não existiam muitas coisas e os dois wapté criadores forma povoando a terra, criando alimentos e animais ..." (SEREBURÃ et alii, 1999, p. 39-40 e 43-44).

O mito segue contando a sequência de criação de animais, outros alimentos, vegetais e animais como as palmeiras de indaiá, acuri, insetos e até chegar na onça (hu) quando os criadores são descobertos e mortos. A sociedade determina sua morte como único meio de controle sobre suas atividades "e os homens ficam donos do criador", negando aos heróis a possibilidade de superabundância de bens e poder. (LOPES DA SILVA 1986: 225)

Do mito pode-se entender como salientou Maybury Lewis, "aspectos mais gerais da cosmologia Xavante", pois este explica a construção do próprio mundo Xavante, ou o Ró, já que este tem um 
sentido maior que engloba além dos Cerrados, o Território, Nossa Terra, Mundo e os espíritos.

\section{As Fitofisionomias dos Cerrados A'uwe Xavante}

As etnoclassificações são abordadas a fim de conhecer a interpretação xavante sobre os cerrados.

Existe uma abundante terminologia para a classificação das fitofisionomias dos cerrados, em que se distinguem várias gradações da vegetação. O número de categorias xavante pode chegar a ser maior do que aquelas dos botânicos que estudaram estas formações. (CARRARA,1997, p. 92)

A etnoclassificação xavante dos cerrados é estabelecida de acordo com as características ambientais e fisionômicas das áreas.

A primeira categoria de classificação xavante dos cerrados é o táxon - rob'udzé - que corresponde ao reino vegetal, formando um conjunto de todos os vegetais.(idem)

Tabela 3 - Comparação entre as classificações Etnoclassificação Xavante dos cerrados - Ró

\begin{tabular}{|c|c|c|}
\hline \multirow{2}{*}{$\begin{array}{l}\text { Termos da etno } \\
\text { classificação Xavante } \\
\text { do Ró-Cerrado } \\
\text { (cf. CARRARA, 1997) }\end{array}$} & \multicolumn{2}{|c|}{ Classificação dos cerrados de acordo com } \\
\hline & COUTINHO (1992) & RIBEIRO \& WALTER (2001) \\
\hline $\begin{array}{l}\text { O termo para cerrado } \\
\text { é Ró. } \\
\text { - todo o verde da } \\
\text { natureza é chamado de } \\
\text { rob'udzé. } \\
\text {-os seres naturais, } \\
\text { plantados ou fixos por } \\
\text { raízes no chão são } \\
\text { classificados como } \\
\text { rob're. }\end{array}$ & $\begin{array}{l}\text { Para o autor o } \\
\text { cerrado é como } \\
\text { um complexo de } \\
\text { formações, formas } \\
\text { savânicas que } \\
\text { variam as suas } \\
\text { características } \\
\text { fisionômicas } \\
\text { estruturais, } \\
\text { aproximando - se } \\
\text { por um lado do } \\
\text { ótimo campestre e } \\
\text { por outro lado do } \\
\text { ótimo florestal.x }\end{array}$ & $\begin{array}{l}\text { Para estes autores o Cerrado comporta formações } \\
\text { florestais, savânicas e campestres. } \\
\text { Formações florestais subdividas em : mata ciliar, } \\
\text { mata de galeria, mata seca, cerradão. } \\
\text { Formações savânicas subdivididos em: cerrado } \\
\text { típico, cerrado ralo, cerrado rupestre, } \\
\text { veredas, parque de cerrado, } \\
\text { palmeiral. } \\
\text { Formações campestres ; campo sujo, campo limpo, } \\
\text { campo rupestre. } \\
\text { O Cerrado sentido amplo abrange : } \\
\text { Cerradão, Cerrado típico, cerrado ralo, cerrado } \\
\text { rupestre, campo sujo, campo limpo, campo } \\
\text { rupestre. } \\
\text { O Cerrado sentido restrito apenas as Formações } \\
\text { savânicas: cerrado típico, ralo e rupestre. }\end{array}$ \\
\hline
\end{tabular}

Tabela 4 - Termos da etnoclassificação Xavante e da ciência de acordo com Riberio \& Walter

\begin{tabular}{|c|c|}
\hline $\begin{array}{l}\text { Termos da etnoclassificação Xavante do Ró - Cerrado } \\
\text { (cf. CARRARA, 1997) }\end{array}$ & $\begin{array}{l}\text { Classificação dos cerrados de acordo com } \\
\text { (cf. Ribeiro \& Walter, 2001) }\end{array}$ \\
\hline $\begin{array}{l}\text { 1. Rob nã - o campo limpo do cerrado. } \\
1.2 \text { as gramíneas - 'du }\end{array}$ & $\begin{array}{l}\text { campo sujo } \\
\text { Não existem árvores, apenas arbustos. Dominam as gramíneas }\end{array}$ \\
\hline $\begin{array}{l}\text { 2. tsirãpré - campo limpo sobre um solo de coloração vermelha } \\
\text { e plano. }\end{array}$ & campo sujo \\
\hline
\end{tabular}




\begin{tabular}{|c|c|}
\hline 3.itehudu é um cerrado ralo ou com poucas árvores. & $\begin{array}{l}\text { Campo cerrado } \\
\text { Ou cerrado ralo, é um pouco mais aberto do que o cerrado típico, } \\
\text { as arvores não ultrapassando } 2 \text { a } 3 \text { metros de altura, cobrem } \\
\text { de } 5 \text { a } 20 \% \text { do solo. }\end{array}$ \\
\hline 4. amhunã e aptsenã categorias de cerrado (não identificados) & $\begin{array}{l}\text { cerrado sentido restrito, cerrado típico } \\
\text { Estrato arbóreo descontinuo, as arvores e os arbustos } \\
\text { apresentam tortuosidade. Também apresenta espécies } \\
\text { gramíneas, ervas e subarbustos. }\end{array}$ \\
\hline \multirow[t]{2}{*}{$\begin{array}{l}\text { 5. rob dzapódo cerradão ou estágio intermediário entre o } \\
\text { cerrado denso e a mata seca }\end{array}$} & $\begin{array}{l}\text { Cerradão } \\
\text { Formação florestal, com dossel contínuo, arvores }\end{array}$ \\
\hline & em geral finas com altura media de 8 a 15 metros. \\
\hline $\begin{array}{l}\text { 6. ubratanã é a mata de bambus, que se mistura ao cerradão } \\
\text { e à mata seca. }\end{array}$ & cerradão \\
\hline 7. marã rowi - mata seca. & Mata seca \\
\hline 8. rowarã formações de cerrado próximas aos cursos d'água. & $\begin{array}{l}\text { Mata ciliar ou mata de galeria } \\
\text { "Mata Ciliar é definida como a vegetação florestal que } \\
\text { acompanha as margens dos rios de médio e grande porte.[...] } \\
\text { Em geral esta mata é relativamente estreita em ambas margens, } \\
\text { dificilmente ultrapassando } 100 \text { metros de largura." } \\
\text { "A Mata de galeria é a vegetação florestal que acompanha os } \\
\text { riachos de pequeno porte e córregos dos planaltos do Brasil } \\
\text { Central, formando corredores fechados sobre o curso de água. } \\
\text { Essas matas geralmente encontram se encravadas no fundo de } \\
\text { vales ou nas cabeceiras de drenagem onde os cursos de água } \\
\text { ainda não escavaram o canal definitivo. } \\
\text { [...] possível identificar certa individualidade florística da } \\
\text { fitofisionomia Mata de Galeria como sendo característica e única } \\
\text { da região do Brasil Central. Por essa razão seria pertinente } \\
\text { aceita-la como típica do bioma Cerrado." }\end{array}$ \\
\hline $\begin{array}{l}\text { 9. tsadarã ou tsõwahunã, pode ser encontrada ao lado da } \\
\text { mata de galeria. }\end{array}$ & Mata de Galeria \\
\hline 10. tsaputunã - pequena mata de interflúvio. & Mata Ciliar \\
\hline 11. buru' rânã margem da mata seca. & Mata Ciliar \\
\hline $\begin{array}{l}\text { 12. marã u ou öwawe maranã - mata de galeria que margeia } \\
\text { o rio das Mortes. }\end{array}$ & Mata Ciliar \\
\hline 13. 'panã - floresta de galeria & Mata de Galeria \\
\hline $\begin{array}{l}\text { 14. marã rãihö pequena formação florestal do tipo amazônica } \\
\text { com árvores de mais de vinte metros de altura. }\end{array}$ & Mata Ciliar \\
\hline
\end{tabular}


Tabela 5 - Etnoclassificação Xavante dos cerrados associada aos diferentes tipos de solo e à fauna típica de cada fitofisionomia

\begin{tabular}{|c|c|}
\hline $\begin{array}{l}\text { 1. AMHU É O LUGAR ONDE AS ÁRVORES SÃO BAIXAS E FECHADAS, } \\
\text { OS ANIMAIS UTILIZAM ESTE LUGAR E MUITOS DORMEM AÍ, SÃO OS } \\
\text { SEGUINTES: ANTA, VEADO, TATU, QUEIXADA, COTIA, EMA. } \\
\text { AS FRUTAS DO CERRADO QUE SÃO ALIMENTOS DOS ANIMAIS, SÃO: } \\
\text { BARU, CORAÇÃO DE ANTA E MUITAS OUTRAS FRUTAS NO RÓ. }\end{array}$ & $\begin{array}{l}\text { CE R R A D O - S E N T I D O } \\
\text { RESTRITO }\end{array}$ \\
\hline $\begin{array}{l}\text { 2. ITEHUDU Neste lugar as árvores são altas, tem buriti e lago. Os } \\
\text { animais que vivem são: veado, tamanduá-bandeira, queixada, anta } \\
\text { e outros. }\end{array}$ & Cerrado ralo \\
\hline $\begin{array}{l}\text { 3. APE É o campo limpo do cerrado que se parece com pasto. O lugar } \\
\text { do veado,anta, ema, tatu, seriema e quase todos os animais ocupam } \\
\text { lugares do Ró. }\end{array}$ & Formação campestre \\
\hline $\begin{array}{l}\text { 4. TSIRAPRE se deu nome porque o cerrado fechado e grande, mas as } \\
\text { árvores são baixas e são iguais. }\end{array}$ & Cerrado \\
\hline $\begin{array}{l}\text { 5. MARÃ padzaihöna hütsidzé,marãhã são as diversas formações } \\
\text { florestais. Neste lugar que comporta mais animais durante inverno, } \\
\text { ficando na sombra, é também lugar de reprodução. Animais típicos } \\
\text { desta formação são : anta, caititu, tamanduá, veados, tatu e tatu- } \\
\text { canastra e outros que vivem nas matas. }\end{array}$ & Formação florestal \\
\hline $\begin{array}{l}\text { 6. TSOWAHU O lugar onde veado costuma ficar e também caititu, } \\
\text { queixadas. Os bichos se alimentam no tsõwahu. }\end{array}$ & $\begin{array}{l}\text { Local próximo as matas de } \\
\text { galeria }\end{array}$ \\
\hline 7. TSA' ITE'RE marâdzapodo & mata circular \\
\hline $\begin{array}{l}\text { 8. BURU'RA Este lugar se localiza dentro no campo limpo do cerrado - } \\
\text { APE, é um tipo de bebedouro onde os caçadores e os animais costumam } \\
\text { tomar água como: veado e anta. }\end{array}$ & $\begin{array}{l}\text { se parece com campo limpo } \\
\text { é o nome do lago que fica no } \\
\text { ape:campo limpo do cerrado }\end{array}$ \\
\hline $\begin{array}{l}\text { 9. TSINÕ' RÕTO Nesse lugar os animais são anta e queixada. } \\
\text { mata pequena limitada onde tem buriti. }\end{array}$ & Mata próxima a buritizal \\
\hline 10. PAPRE & barreira nas margens do rio \\
\hline $\begin{array}{l}\text { 11. OTÕ } \\
\text { Lagoa é um lugar dos peixes onde se desenvolvem e recriam, como: } \\
\text { piranha, tucunaré, traíra, peixe-elétrico, arraia, jacaré, sucuri e esses } \\
\text { são donos desse lago, mas tem outros peixes. }\end{array}$ & lago \\
\hline $\begin{array}{l}\text { 12. OWAWE } \\
\text { Rio grande }\end{array}$ & Rio grande ou rio das Mortes \\
\hline
\end{tabular}

As etnoclassificações podem apresentar diferentes versões e variações entre os próprios Xavante, ou seja, o resultado de uma pesquisa não representa o conhecimento de todos, e não esgota outras possíveis classificações ou complementações da apresentada.(CARRARA, 1997:122) Neste sentido apresenta-se uma outra classificação coletada em T. I. Pimentel Barbosa.

A classificação dos cerrados da tabela 5 foi relatada por Tsidanere da aldeia Wederã, na T. I.
Pimentel Barbosa (2006). Segundo ele, os Xavante nomeiam as diferentes fisionomias dos cerrados de acordo com a vegetação predominante. Em sua classificação também há os solos correspondentes, e cita as principais espécies frutíferas que servem de alimento à fauna.

\section{Considerações finais}

Os levantamentos apresentam a riqueza dos saberes de homens e mulheres, pois, 
ambos guardam grandes conhecimentos sobre a vegetação dos cerrados.

As classificações Xavante da natureza, entrelaçam sentidos cosmológicos com conhecimentos morfológicos e ecológicos. (CARRARA, 1997, p. 120 e 281).

Os mitos ensinam como se originaram os animais, e assim como em outras sociedades indígenas, também para os Xavante há uma noção de "um estado original de indiferenciação entre os humanos e os animais" [...]"os mitos contam como os animais perderam os atributos herdados ou mantidos pelos humanos. Os humanos são aqueles que continuaram iguais a si mesmos: os animais são ex-humanos, e não os humanos ex-animais [...]" (VIVEIROS DE CASTRO, 1996, p. 118)

São, portanto, as "concepções cosmológicas que informam a maneira de se observar os seres da natureza" (Calbazar, 2005, p. 12), e assim o mundo é ordenado. Entre os Xavante o mito de Parinai'a ensina como se construíram os cerrados, e assim a sua divisão fitogeográfica com todos os seres, da "natureza" e da "sobrenatureza", que aí vivem e que constroem, juntamente com os Xavante o Ró.

Atualmente, a intensa devastação dos cerrados tem provocado inúmeros impactos socioambientais nas terras indígenas, e em especial na cultura Xavante a qual, como visto, tem relações fundamentais com os cerrados considerados seu mundo.

Finalizamos com suas próprias palavras : "o Xavante depende dos cerrados e os cerrados dependem dos Xavante", são portanto cultura, território e ambiente interdependentes e ameaçados com a ocupação dos cerrados pelo agronegócio.

\section{Agradecimentos}

Agradeço ao povo A'uwe Xavante que me acolheu e propiciou os ensinamentos de sua cultura e ao
CNPQ pelo apoio para realização da pesquisa. Dezembro de 2009.

\section{Notas}

1. "Malinowski sem ter sido o primeiro a fazer pesquisa de campo tal como a entendemos hoje, foi o primeiro a elaborar sua teoria, [...] alem de nos ter legado uma das mais cuidadosas e exaustivas descrições de uma sociedade estranha. [...] viveu durante a primeira guerra mundial nas ilhas Trobriand do Pacifico [...] Sua rica experiência de campo, bem como as bases metodológicas por ele lançadas, ainda continuam a estimular a reflexão dos antropólogos sobre sua prática fundamental ; a convivência diária com o 'outro' a fim de conhece-lo." (ALBA ZALUAR ,1980:10)

2. RODRIGUES, CARMEM LUCIA - Limites do Consenso : Territórios Polissêmicos na Mata Atlântica e a gestão ambiental participativa - tese (doutorado) dep.Geografia FFLCH/USP -2001

\section{Bibliografia}

BRANDÃO, Carlos Rodrigues (Org.). Pesquisa Participante. $8^{a}$ ed. e $2^{a}$ reimpressão. São Paulo: Brasiliense, 2001.

Repensando a Pesquisa Participante. $3^{a}$ edição. São Paulo: Brasiliense, 1987.
3. "na década de 70, quase a totalidade dos exemplos agrupados por Carlos R. Brandão, em Repensando a pesquisa participante, estavam relacionados ás pastorais da igreja católica que se colocariam 'a serviço de projetos de construção de bases sociais do poder popular"'".

(Rodrigues 2001, p. 16,17)

4. Lopes da Silva (1986), analisa o mito Parinai'a no sentido de esclarecer a categoria de seu estudo, i'amõ ou seja, "as relações que existem entre duas pessoas que se chama mutuamente por i'amõ, companheiros." (1986.:230)

5.Depoimento coletado pela pesquisadora em 2007, na T.I.Sangradouro, Aldeia Idzou'hu.

BIASE, Helena \& Xavante, Ruriõ Lucas. A História da aldeia Abelhinha, 1999

CALBAZAR, Aloísio (org). Peixe e Gente no Alto Rio Tiquié: conhecimentos Tukano e Tuyuka, ictiologia, etnologia. São Paulo: Instituto Socioambiental, 
2005.

CLAVAL, Paul. O papel da nova geografia cultural na compreensão da ação humana In ROSENDAHL,ZENY \& CORREA, ROBERTO LOBATO (org.) - Matrizes da Geografia Cultural - Ed.UERJ 2001.

CARRARA, Eduardo. Tsi Tewara um vôo sobre o cerrado Xavante. Dissertação Mestrado. Departamento de Antropologia FFLCH / USP, São Paulo 1997.

GIACCARIA \& HEIDE Adalberto. Xavante (Auwe Uptabi: povo autêntico): pesquisa históricoetnográfica. São Paulo: Dom Bosco, 1972.

GOMIDE, Maria Lucia C. Povos Indígenas do Cerrado Territórios Ameaçados -dissertação( mestrado) Departamento de Geografia - FFLCH/ USP São Paulo2004.

Marãnã bödödi a territorialidade Xavante nos caminhos do Ró tese (doutorado) Departamento de Geografia - FFLCH/USP São Paulo 2009.

GRAHAM, Laura. textos sobre povo Xavante in: Enciclopédia dos povos indígenas - www. socioambiental.org.br - acesso dia 15/08/ 2008. LADEIRA, Maria Inês M. Espaço geográfico Guarani-MBYA : significado, constituição e uso. Tese (Doutorado) Departamento de Geografia FFLCH/USP. São Paulo, 2001.

LOPES DA SILVA, Aracy. Xavante: casa - aldeia - chão - terra - vida. In: NOVAES, Silvia C. (Org.). Habitações Indígenas. Pg 33- 56, 1981. São Paulo: Nobel: Ed. da Universidade de São Paulo, 1983.

Novos tempos, velhas histórias In:
Revista Brasileira de Ciências Sociais - RBCS vol 14 n.40 junho, São Paulo, 1999.

Dois séculos e meio de História Xavante In: Cunha, Manuela Carneiro da (org.) História dos índios no Brasil. São Paulo: Secretaria Municipal de Cultura/Companhia das Letras/Fapesp, 1992.

Nomes e amigos - da pratica Xavante a uma reflexão sobre os Jê -FFLCH-USP - 1986.

MAYBURY-LEWIS, David. A Sociedade Xavante (Akwe Shavante Society, 1967). Tradução: Aracy Lopes da Silva. Rio de Janeiro: Francisco Alves, 1984. [1967].

MARIMON, Beatriz \& FELFILI, J. Ethnobotanical Comparison Pau Brasil Forests In : A Xavante Indian And Non-Xavante Community -2001.

RIBEIRO,J.F. \& WALTER, B.M.T. As Matas de Galeria no Contexto do Bioma Cerrado In:RIBEIRO, J.; FONSECA, CEL; SILVA, J.C.S (org.) Cerrado: Caracterização e Recuperação de Matas de Galeria -PLANALTINA- EMBRAPA -2001

SEREBURÃ, Hipru, Rupawe, Serezabdi e Sereñimirãmi . Wamrêmé Za'ra: nossa palavra: Mito e história do povo Xavante. São Paulo: Editora Senac, 1998.

TUAN,Yi-Fu. Espaço e lugar: a perspectiva da experiência. São Paulo: Difel, ([1977]- 1983

VIVEIROS de Castro, Eduardo Batalha. A inconstância da alma selvagem e outros ensaios de antropologia. São Paulo: Ed. Cosac \& Naify, 2002.

XAVANTE, Lucas Ruriõ. A vida do Sr. Adão Toptiro - Trabalho de Conclusão de Curso Licenciatura em Ciências Sociais, Terceiro Grau Indígena - Barra do Bugre, MT: 2006. 